\title{
A PAISAGEM DA BACIA DO RIO PITANGUI SOBRE A ESCARPA DEVONIANA, PONTA GROSSA, PARANÁ
}

\section{Pitangui river watershed landscape in the Devonian Cuesta, Ponta Grossa, Paraná, Brazil}

\author{
Tiaro Katu Pereira \\ Mestre em Gestão do Território . Doutorando em Engenharia Florestal. \\ Universidade Federal do Paraná, Curitiba, Paraná, Brasil \\ tkpereira@live.com \\ Rosemeri Segecin Moro \\ moro.uepg@gmail.com \\ Melissa K. F. de Souza Nogueira \\ melissaknog@yahoo.com.br \\ Wolliver Dias \\ wolliverdias@hotmail.com
}

Artigo recebido em 21/07/2013 e aceito para publicação em 06/09/2013

RESUMO: A Ecologia da Paisagem vem se tornando uma importante ferramenta para a tomada de decisões no ordenamento do território. Nessa ótica, este trabalho analisa a composição e configuração espacial da paisagem do Rio Pitangui, antecedente a formação dos planaltos paranaenses, em sua entrada pela Escarpa Devoniana. As unidades de paisagens (UP) florestais e campestres foram delimitadas e embasaram os cálculos das métricas de paisagem. As UPs foram classificadas de acordo com sua extensão e sua funcionalidade em: trampolins, corredores e fragmentos. Em um total de 8.015 ha, foram identificados 103 fragmentos florestais (11,4\% da área) e 82 campestres (49,4\%), restando 39,2\% de área antropizada por pastagens, cultivos e reflorestamentos. As áreas campestres apresentaram tamanho médio maior e conformação espacial mais regular do que as áreas florestais, menores e mais alongadas. Existem fragmentos campestres extensos numa paisagem com predominância de áreas naturais sobre as antrópicas. As características da paisagem desse segmento são resultados não só da interferência antrópica, mas principalmente da evolução da paisagem frente às flutuações climáticas do Quaternário recente. As áreas naturais desta porção da bacia apresentam condições espaciais favoráveis no que se refere à manutenção da biodiversidade, como extensão e continuidade. Há diferenças no padrão de uso do solo nas áreas estudadas, a porção norte apresenta-se mais antropizada enquanto que na porção sul as áreas naturais estão mais preservadas.

Palavras-Chave: Fragmentação, Ecologia da Paisagem, Estepe gramíneo-lenhosa. 
ABSTRACT: The Landscape Ecology has become important for decisions on land use. This work presents the spatial configuration of the Pitangui river landscape in the Devonian Cuesta. The Landscape Units (LU) were classified as anthropogenic matrix, forest and grasslands patches. In a total of 8,015 ha, they were identified 103 forest fragments (11.4\% of the area) and 82 grasslands fragments $(49,4 \%)$, being 39.2\% of anthropogenic areas. The grasslands patches are bigger and more regular shaped whereas the forest one. The present landscape has resulted not only of the human interference, but mainly of the landscape evolution under the Late Quaternary climatic flutuations. The natural areas of this portion of the Pitangui watershed showed favorable spatial conditions with regarding to the biodiversity maintenance. There are extensive grasslands fragments in a predominant natural landscape. There are differences in the land use pattern: the northern portion appears more disturbed than the southern portion with natural areas best preserved.

Keywords: Fragmentation, Landscape Ecology, Grasslands.

\section{INTRODUÇÃO}

A Biologia da Conservação tem se utilizado da análise de paisagem para avaliar a funcionalidade dos elementos espaciais e a disposição das espécies. Os índices de paisagem, enquanto descritores espaciais oferecem uma valiosa visão das similaridades e diferenças de estrutura e função entre mosaicos de cobertura vegetal em diferentes paisagens. A estrutura refere-se às relações espaciais entre ecossistemas distintos, a distribuição de energia, materiais e espécies em relação ao tamanho, forma, quantidade, tipos e configuração dos componentes do ecossistema. Já a função é representada pela interação entre os elementos espaciais: fluxo de energia, materiais e espécies entre os componentes ecossistêmicos (FORMAN; GODRON, 1986).

Tendo em vista as características, as funções e as atuações sobre a paisagem, principalmente influenciadas por atividades antrópicas, a mesma pode-se configurar de diversas maneiras, formando um verdadeiro mosaico espacial com seus fragmentos. Assim, Forman e Godron (1986) caracterizam os fragmentos da paisagem em três componentes básicos: matriz, fragmentos e corredor. A matriz pode ser definida como elemento dominante, que controla o funcionamento e a dinâmica da paisagem, geralmente tem composição homogênea e entre os elementos da paisagem é o mais extenso e conectado, mantendo grande controle sobre a área (FORMAN; GODRON, 1981, 1986). Os fragmentos se referem aos remanescentes de um tipo de cobertura contrastante a uma matriz predominante (FORMAN; GODRON, 1981, 1986). A ligação entre fragmentos através de corredores penetra quase todas as paisagens de diversas maneiras. Os corredores podem ser de três tipos: linhas-corredores, de forma linear (estradas, trilhas, cercas, diques, canais e outros); faixas-corredores, mais largas que as linhas e usualmente com presença de vegetação (estradas, sistemas de torres de energia); e cursos d'água, principalmente considerando a vegetação ao longo dos mesmos (FORMAN; GODRON, 1981, 1986), designadas de zonas ripárias.

A composição e a organização espacial destes componentes são fatores que influenciam diretamente a funcionalidade da paisagem, pois implicam no grau de conectividade entre os fragmentos, proporcionado pela matriz. De acordo com Casimiro (2001), o número de fragmentos de um determinado habitat pode influenciar uma grande variedade de processos ecológicos, como por exemplo, a determinação do número de sub-populações de uma população espacialmente dispersa, a estabilidade das interações e oportunidades de coexistência em sistemas de predador-presa e sistemas competitivos. A fragmentação de habitats é responsável pelo efeito de borda, um conjunto de processos na área de transição entre matriz e fragmentos (SANTOS et al., 2010). Para Borges et al. (2004), entre as principais conseqüências da fragmentação estão as alterações no microclima como na umidade do ar, temperatura e radiação solar, particularmente nas bordas dos fragmentos, com perda de biodiversidade.

Este trabalho buscou demonstrar a composição e configuração espacial da paisagem do Rio Pitangui ao adentrar a Escarpa Devoniana, no município de Ponta Grossa, Paraná. Esta bacia hidrográfica agrupa 
características geológicas, geomorfológicas, vegetacionais e de uso do solo extremamente representativas da paisagem dos Campos Gerais, sendo por este motivo selecionada para aplicação de métricas que levem à compreensão da organização espacial gerada pelas ações antrópicas sobre paisagens no reverso da Cuesta.

\section{MATERIAL E MÉTODOS}

\section{Área de estudo}

O Pitangui é um rio antecedente que, com nascentes e curso meandrante no Primeiro Planalto Paranaense (PPP), após seu represamento no reservatório de Alagados, penetra no Segundo Planalto
Paranaense (SPP), atravessando a Escarpa Devoniana num curso encaixado em fraturas geológicas até desaguar no Rio Tibagí (MELO et al., 2010). A bacia hidrográfica do Pitangui possui cerca de um terço de seu território situado no PPP, enquanto os dois terços restantes situam-se no relevo de transição no SPP.

O recorte espacial deste estudo foi adaptado da compartimentação prévia da bacia do Pitangui proposta por Pereira et al. (2010), e considera o segmento denominado "Compartimento 3", ou "São Jorge", devido ao rio com o mesmo nome, que caracteriza esse setor. A área abrange 8.015,203 ha (Figura 1) sobre a Escarpa Devoniana, numa paisagem de vales encaixados e morros com topos aplainados, formando cânions e cascatas (MELO et al., 2010).

Figura 1: Localização da área de estudo. Recorte adaptado da compartimentação da bacia hidrográfica do Rio Pitangui, Ponta Grossa, PR.

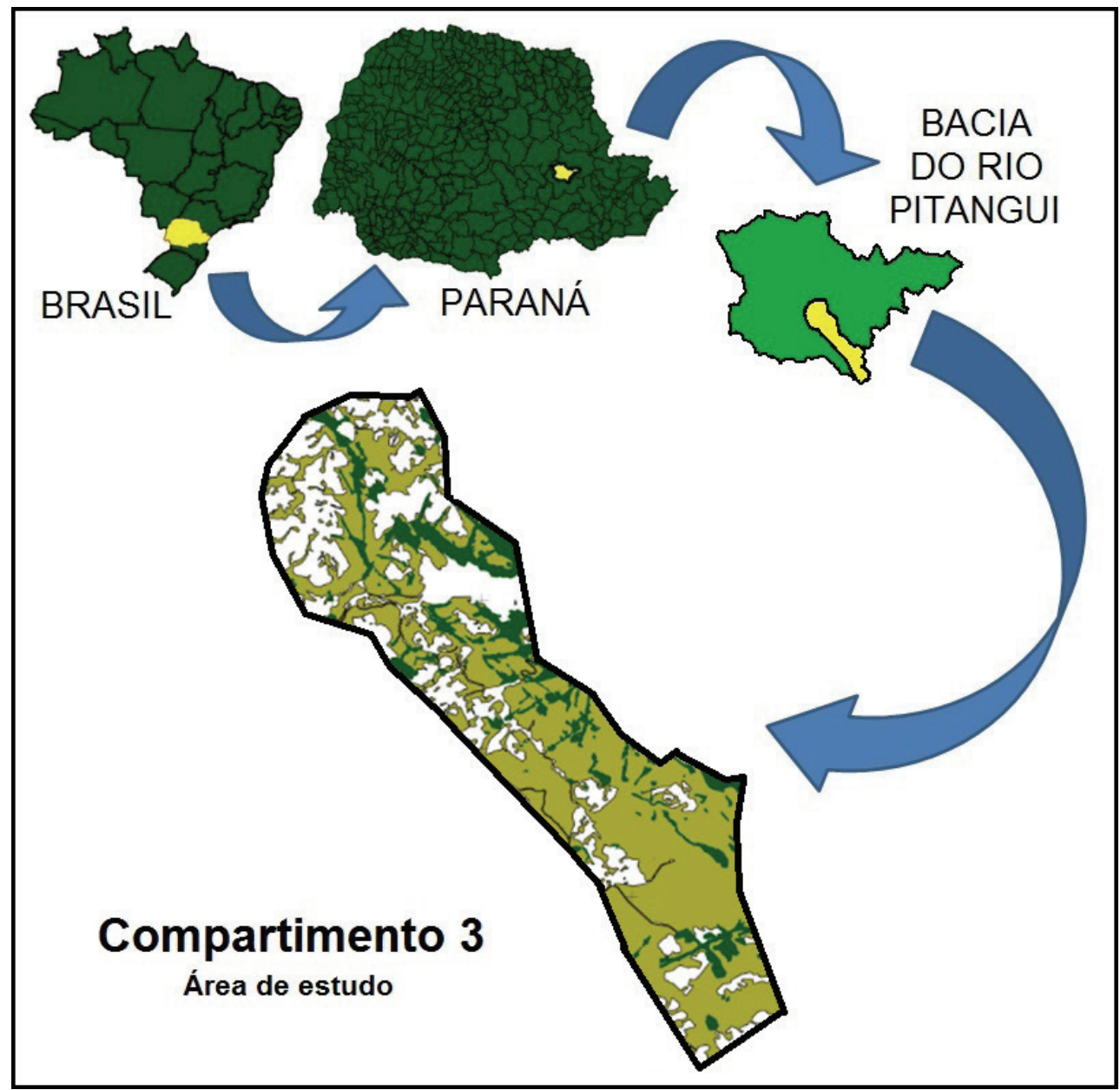

Fonte: Pereira et al. (2010). 
A estrutura litológica da região, composta por rochas sedimentares expostas pelo soerguimento e erosão do terreno (MELO et al., 2010), representa a fronteira entre o Primeiro e o Segundo Planalto Paranaense. Trata-se de uma região ecotonal, onde a vegetação do PPP, pertencente à zona fitoecológica Floresta Ombrófila Mista Montana forma um mosaico climático-edáfico com a Estepe Gramíneo-Lenhosa do SPP (IBGE, 2012), ocupando fendas e depressões.

Predominam Cambissolos Háplicos e Neossolos Litólicos formados sobre o arenito da Formação Furnas, que origina solos rasos, arenosos e bastante suscetíveis a processos erosivos (EMBRAPA, 2002). O clima na região da bacia do Rio Pitangui é do tipo Cfb da classificação de Koeppen (MAACK, 2002), isto é, zona temperada sempre úmida, com mais de cinco geadas anuais. A temperatura média anual está entre $16^{\circ} \mathrm{C}$ e $22^{\circ} \mathrm{C}$ e os ventos tem predominância NE no verão e NW no inverno (CRUZ, 2007). Quanto ao regime de chuvas, a precipitação média anual situa-se entre $1.400 \mathrm{~mm}$ e $1.800 \mathrm{~mm}$, sendo o período mais seco é de junho a agosto, com média de $250 \mathrm{~mm}$ a $350 \mathrm{~mm}$; o período mais chuvoso é de dezembro a fevereiro, com média de $500 \mathrm{~mm}$ a $600 \mathrm{~mm}$.

A região de estudo é considerada de alta e extremamente alta importância para a conservação, de acordo com Áreas Prioritárias para a Conservação do Probio (MMA/SBF, 2002), reconhecidas oficialmente pelo Governo Federal através do Decreto 5092/2004 e da Portaria MMA 09/2007, e de áreas campestres valiosas no Cone-Sul (GRANDO et al., 2004). A área está abrangida pela APA Estadual da Escarpa Devoniana e parte está protegida também pelo Parque Nacional dos Campos Gerais (PNCG).

Toda a bacia hidrográfica do Rio Pitangui é caracterizada por intensa atividade agropecuária (ROCHA; WEIRICH NETO, 2010), e reflorestamentos com espécies exóticas, com riscos de contaminação biológica dos campos nativos remanescentes (ZILLER; GALVÃO, 2002).

\section{Procedimentos metodológicos}

Para o delineamento das Unidades de Paisagem (UP) pela fotointerpretação supervisionada, utilizou-se ortoimagens do sensor SPOT5 (Paraná Ci- dade, 2005), com resolução espacial de 10 metros, na escala 1:50.000, arquivos vetorizados da delimitação dos compartimentos da bacia do Pitangui, e curvas de nível (eqüidistância de 20 metros) da área de interesse. A digitalização das UPs foi realizada mediante a vetorização dos polígonos criando um banco de dados espaciais georreferenciados no programa Arcview, disponibilizado pelo Departamento de Geociências da Universidade Estadual de Ponta Grossa (UEPG). A identificação das UPs considerou o aspecto visual e o porte da cobertura do solo, em termos de coloração e textura da imagem.

Os fragmentos delimitados foram categorizados em unidades de paisagem (UP) de campo e de floresta, e, por meio do programa FRAGSTATS (MCGARIGAL; MARKS, 1995), foram calculadas as seguintes métricas para paisagem:

a. TA - área total da paisagem em hectares;

b. CA - área total de cada UP em hectares;

c. Ho-diversidade da paisagem-quantifica a diversidade de unidades de paisagem consideradas. O valor de SIDI pode variar entre 0 e 1 , sendo que para valores iguais a 0 , a paisagem unicamente é constituída por um tipo de habitat ou mancha. SIDI aproxima-se de 1 à medida que o número de diferentes tipos de habitat aumenta e a proporção da distribuição da área em cada um se torna mais equilibrada;

d. E - equitabilidade - proporção da área total ocupada pelas UPs; varia de 0 (há grande disparidade entre as áreas das UPs) a 1 (todas as UPs possuem a mesma área);

e. Do - dominância - refere-se a dominância de uma ou mais unidades (campo ou floresta, neste caso) em uma paisagem.

Para cada Unidade de Paisagem - UP (campo e floresta):

a. NP - número de fragmentos;

b. MPS - tamanho médio dos fragmentos;

c. FR - freqüência relativa dos fragmentos;

d. \% LAND - percentagem ocupada pela UP no recorte espacial; 
e. LPI - índice de fragmento maior - indica a porcentagem da área total de cada UP ocupada pelo maior fragmento;

f. $\quad$ PD - densidade de fragmento - número de EP de cada UP em 100 hectares de paisagem.

Para os fragmentos:

a. FRACT - Dimensão Fractal, sendo duas vezes o logaritmo do perímetro do fragmento dividido pelo logaritmo da área do fragmento. Varia de 1 a 2, quanto mais próximos de 1 (um) mais isodiamétrico será o polígono.

b. IC - Índices de Circularidade dos fragmentos (BORGES et al., 2004). Resulta da raiz quadrada da área do polígono dividido pela área de um círculo de mesmo perímetro $(\mathrm{P})$ do polígono. Varia de 0 a 1 , quanto mais próximos de 1 (um) mais isodiamétrico será o polígono.

c. Média, mediana, desvio padrão e a amplitude de valores para os índices de forma dos fragmentos.

Os fragmentos foram classificados, de acordo com o tamanho, em quatro grupos: a) menores que 1,0 ha; b) com tamanho entre 1,0 e 9,9 ha; c) entre 10,0 e 49,9 ha; e d) maiores que $50 \mathrm{ha}$.

Os elementos da paisagem (EP) foram classificados por meio do Software GUIDOS (CVOGT, EC-JRC, 2010), considerando as classes: Fragmento (áreas core); Corredores (elementos lineares que ligam dois fragmentos anteriormente conectados); e Trampolins (ou ilhas, que são pequenas áreas de habitat dispersas pela matriz que podem facilitar os fluxos entre fragmentos para algumas espécies) (METZGER, 2001), adotando como critérios um valor de borda de 20 metros.

\section{RESULTADOS E DISCUSSÃO}

Foram definidas três Unidades de Paisagem (UPs), representadas pela matriz (área antropizada), pelas áreas campestres nativas, e pelas áreas florestais em seus diferentes estágios de sucessão (Figura 2). Em uma área total (TA) de $8.015,203$ ha, foram delineados 103 fragmentos campestres, que ocupam 49,4\% da área, e 82 fragmentos florestais distribuídos em $11,4 \%$ da área. Outros 39,2\% são representados pela matriz (Tabela 1).

A diversidade de paisagem (Ho) foi 0,68 , com Equitabilidade (E) de 0,62 e Dominância (Do) de 0,41. Estes índices apontam, para a paisagem do Compartimento 3, a prevalência da cobertura campestre sobre as demais, embora não se possa considerar dominante na paisagem.

Tabela 1: Área das Unidades de Paisagem da bacia do Rio Pitangui na Escarpa Devoniana, Ponta Grossa, PR.

\begin{tabular}{ccc}
\hline $\begin{array}{c}\text { Unidade de } \\
\text { Paisagem }\end{array}$ & Área (hectares) & $\mathbf{\%}$ \\
\hline Matriz & $3.139,69$ & 39,2 \\
Campo & $3.957,46$ & 49,4 \\
Floresta & 918,05 & 11,4 \\
Área total & $8.015,20$ & 100,00 \\
\hline
\end{tabular}

Org. dos autores. 
Figura 2: Classificação das Unidades de Paisagem da bacia do Rio Pitangui na Escarpa Devoniana, Ponta Grossa, PR.

\section{BACIA HIDROGRÁFICA DO RIO PITANGUI Compartimento 3 - "São Jorge" Fragmentação da Paisagem}

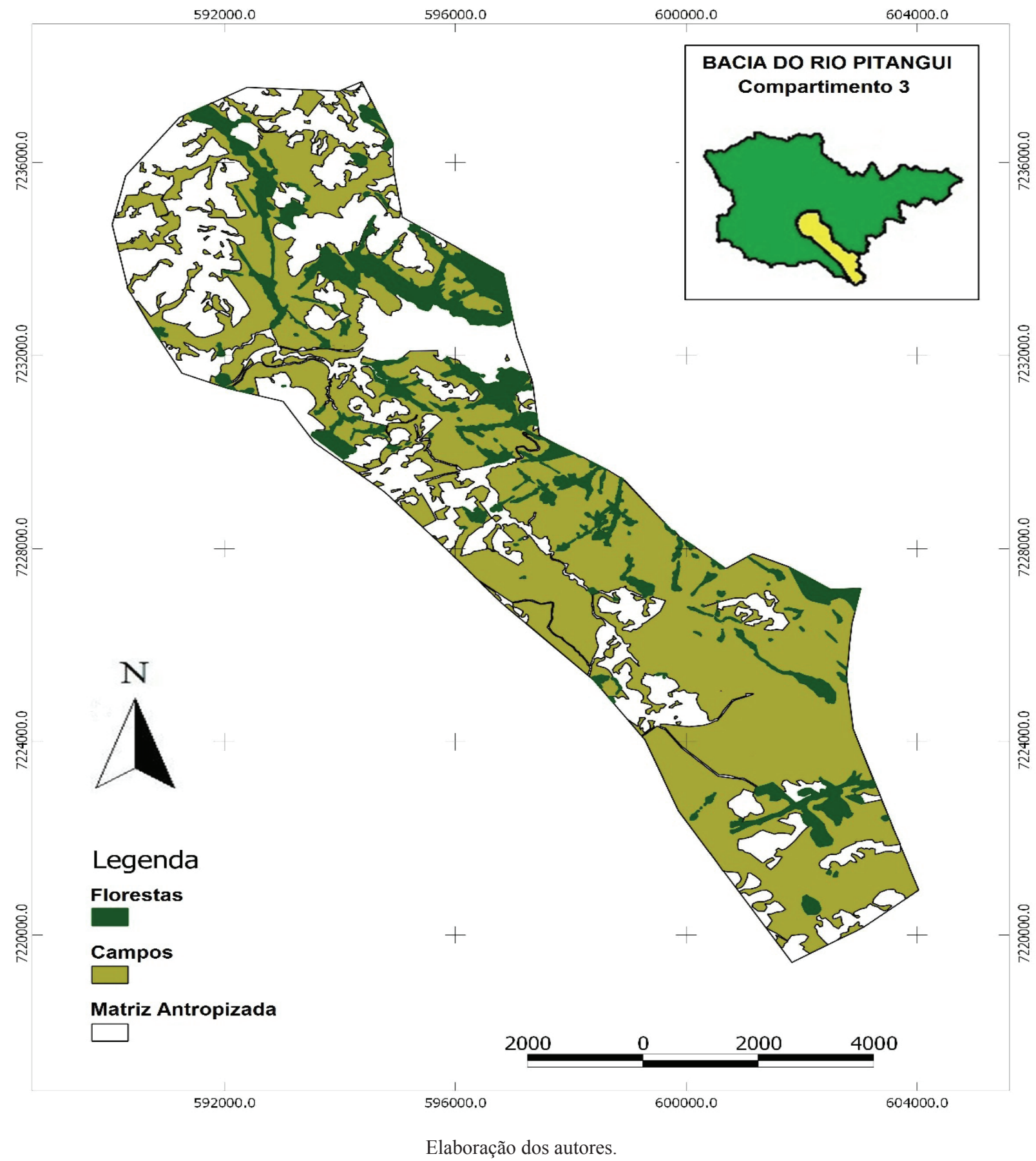


Avaliando as métricas de paisagem calculadas (Tabela 2), observa-se que as dimensões dos fragmentos campestres são bastante superiores aos florestais, com tamanho médio de 47,83 ha $(\sigma=214,7)$, enquanto que os de floresta correspondem a 8,57 ha $(\sigma=26,9)$. Dalazoana $(2010)$, analisando os fragmentos campestres do Parque Nacional dos Campos Gerais por tipologia vegetal, encontrou valores de tamanho médio bem menores quando se leva em conta as características intrínsecas diferenciadas de "campo" na região - 24,4 ha para campos secos (estepe stricto sensu), 13,6 ha para os campos rochosos e apenas 3,5 ha para as depressões brejosas (estepe higrófila). Para os campos planálticos do nordeste do Rio Grande do Sul (CORDEIRO; HASENACK, 2009), o tamanho médio de fragmentos campestres é de 18,6 ha, e para os florestais, apenas 0,25 ha.

As áreas florestais apresentaram densidade superior às campestres, apontando para sua maior fragmentação. Isto também pode ser observado nos valores dos índices de fragmento maior (LPI), quase o dobro para o campo $(47,23 \%)$ em relação à floresta $(25,32 \%)$. É uma configuração esperada para áreas de reverso de Cuesta, em virtude de suas características geomorfológicas, com predomínio campestre interrompido por áreas de avanço florestal a partir do talus através de fendas (pequenos cânions) na cornija. Para Nanuncio (2009), a média de tamanho de fragmentos florestais lineares foi de 22,2 ha, com desvio padrão de 136,3 ha. A autora evidenciou a inutilidade deste tipo de análise em função da média e utilizou a mediana, que no caso de Piraí da Serra foi de 1,65, para demonstrar que, em termos absolutos, metade dos fragmentos de floresta era menor do que 2 ha. Observando-se a mediana calculada para as áreas da bacia do Pitangui sobre a Escarpa Devoniana, metade dos fragmentos campestres (44) tem menos que 3,29 ha e metade dos fragmentos florestais (51) têm área menor que 1,45 ha.

Ainda que esses processos de fragmentação natural sejam devido a variações climáticas do Período Quaternário (BEHLING, 1997), o tamanho médio dos fragmentos, especialmente dos campestres, também se associa intimamente com as formas de uso e ocupação do solo, de modo que a dimensão apresentada por esses fragmentos é resultado da maior ou menor taxa de remoção da vegetação (ação antrópica) dessas áreas.

Tabela 2: Métricas da paisagem do Rio Pitangui na Escarpa Devoniana, Ponta Grossa, PR.

\begin{tabular}{lccccccc}
\hline Unidade de Paisagem & NP & MPS (ha) & $\sigma$ & Mi & FR & PD & LPI \\
\hline Campo & 82 & 47,83 & 214,7 & 3,29 & 0,44 & 1.023 & 47,23 \\
Floresta & 103 & 8,57 & 26,9 & 1,45 & 0,55 & 1.285 & 25,32 \\
\hline
\end{tabular}

$\mathrm{NP}=$ Número de Polígonos, MPS=Tamanho Médio dos Polígonos; $\sigma=$ desvio padrão dos tamanhos; Mi=Mediana dos tamanhos; FR=Frequência Relativa dos Polígonos; PD=Densidade dos Polígonos em 100 ha; LPI= Índice de Fragmento Maior. Org. dos autores.

$\mathrm{Na}$ análise da distribuição das freqüências dos tamanhos dos fragmentos (Figura 3), as áreas florestais apresentaram 87 fragmentos $(84,5 \%)$ com até 10 ha, 12 fragmentos com tamanho entre 10 e 50 ha $(11,6 \%)$, e apenas quatro maiores a 50 ha $(3,9 \%)$. As áreas campestres apresentaram 56 fragmentos $(68,3 \%)$ com até 10 ha, 18 fragmentos com tamanho entre 10 e 50 ha $(21,9 \%)$, e oito com tamanho maior que 50 ha $(9,8 \%)$.
A distribuição das frequências de tamanho dos fragmentos foi similar para campo e floresta, onde a maioria dos fragmentos é menor que 10 ha. Embora não existam análises acerca do tamanho mínimo de fragmentos viáveis a conservação de espécies para os campos planálticos do Bioma Mata Atlântica, Ribeiro et al. (2009) declaram a extrema importância dos fragmentos menores do que 50 ha na manutenção da conectividade da paisagem. 
Figura 3: Número de fragmentos de campo e de floresta por classe de tamanho da paisagem do Rio Pitangui na Escarpa Devoniana, Ponta Grossa, PR.

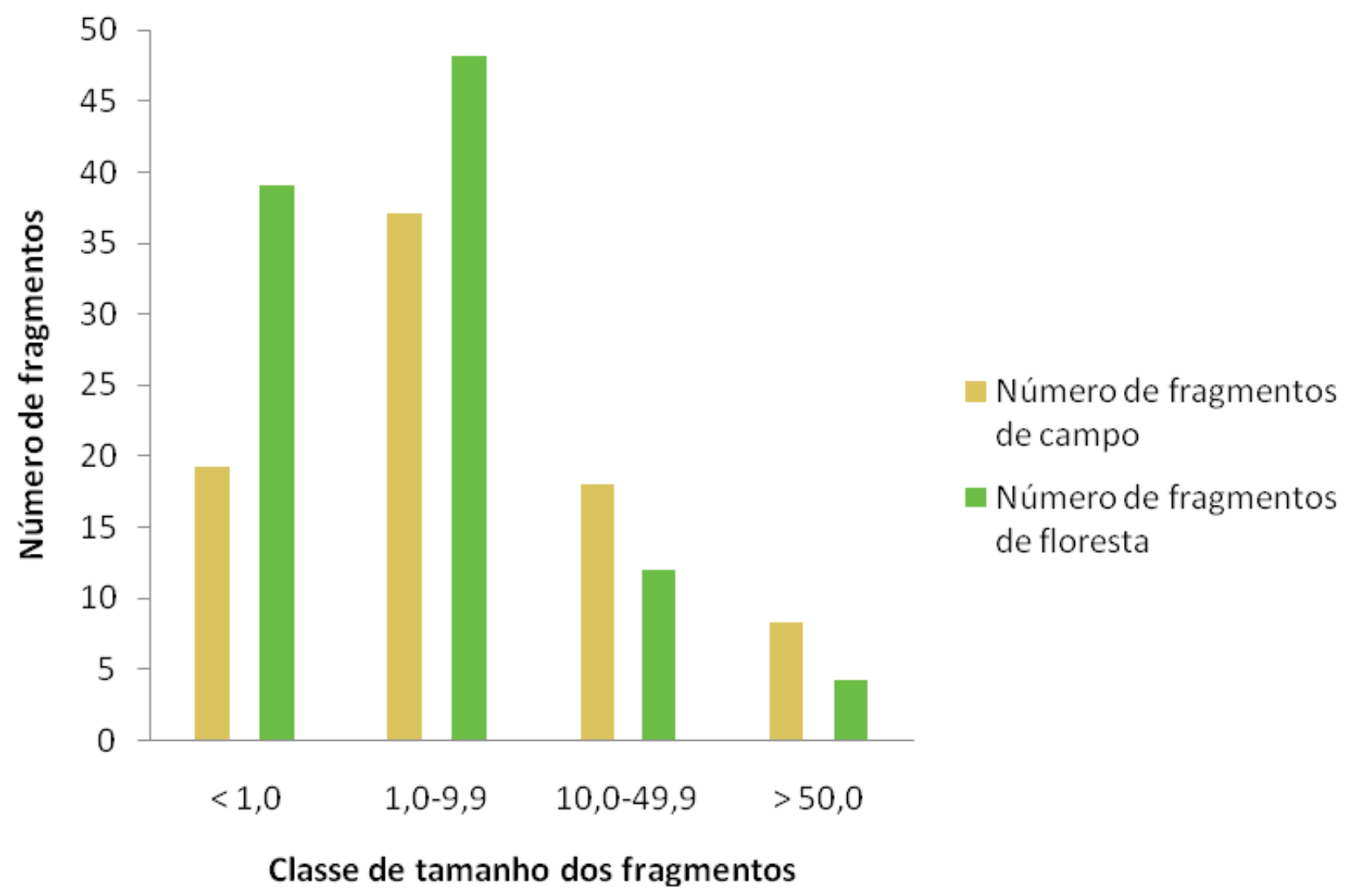

Elaboração dos autores.

Em relação à forma dos fragmentos, as médias dos Índices de Circularidade para as áreas campestres foram de 0,56 $( \pm 0,20)$ e para florestas de 0,62 ( \pm $0,20)$. Estes valores demonstram que os fragmentos tanto de campo quanto de floresta têm tendência para áreas com formato isodiamétrico, mas também ocor- rem fragmentos alongados apresentando IC próximo a 0,0 (Figura 4). Para Dalazoana (2010), o IC médio das estepes nesta porção da escarpa está entre 0,50 e 0,60 . Com relação às florestas na escarpa, o IC médio observado foi de 0,6 (NANUNCIO, 2009; DALAZOANA, 2010). 
Figura 4: Distribuição dos fragmentos de campo nativo e floresta, segundo Índice de Circularidade (IC) da paisagem do Rio Pitangui na Escarpa Devoniana, Ponta Grossa, PR.
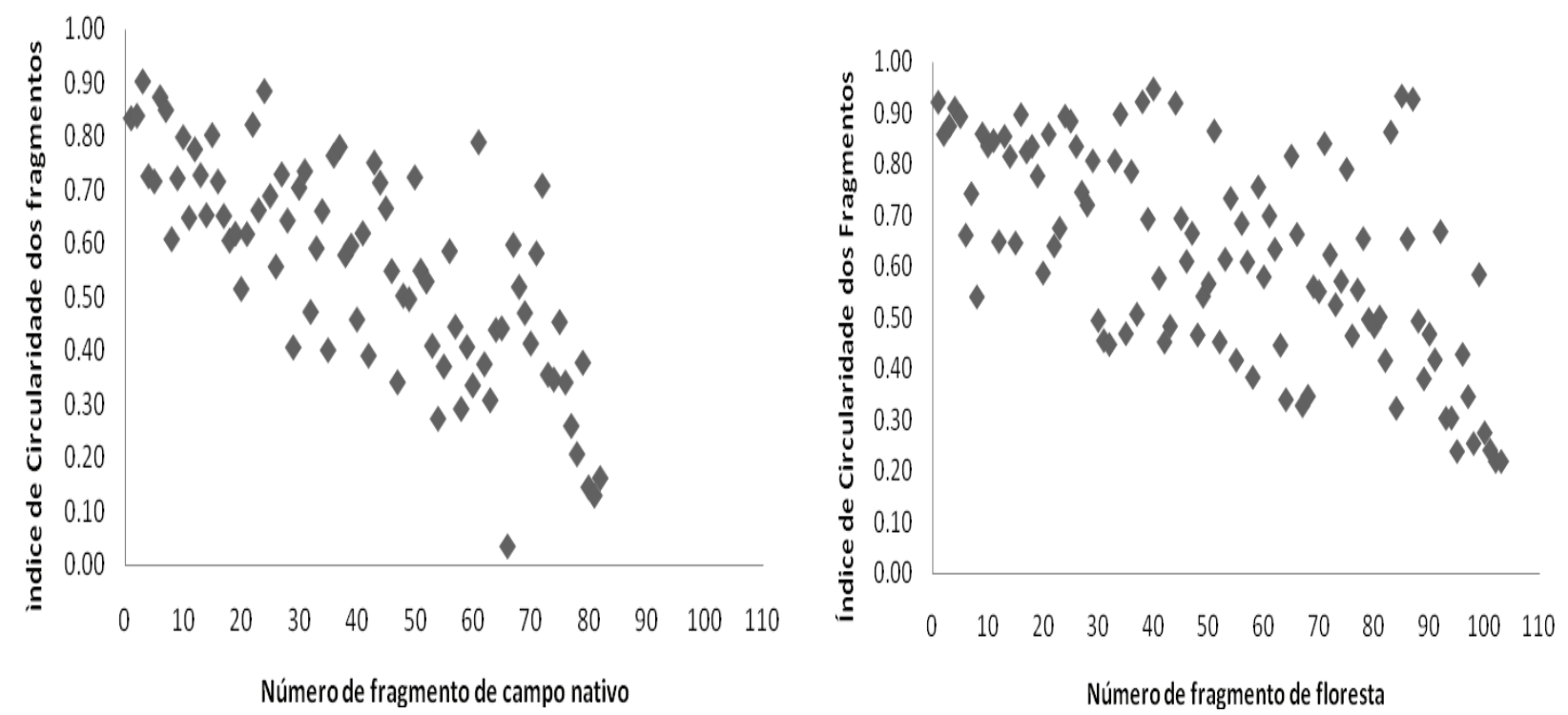

Elaboração dos autores.

Os valores médios de dimensão fractal (FRACT), de 1,36 para campo nativo e de 1,37 para floresta (Figura 5), inferem que as duas UP apresentam fragmentos com formas consideravelmente regulares. Dalazoana (2010) encontrou FRACT médio de 1,39 para as estepes do Parque Nacional dos Campos Ge- rais, sendo que o valor diferia ligeiramente para os fragmentos de campos secos $(1,40)$, campos brejosos $(1,42)$ e campos rochosos $(1,38)$; para as florestas encaixadas nos cânions e capões de floresta, o FRACT médio observado foi de 1,18 .

Figura 5: Distribuição dos fragmentos de floresta e campo nativo, segundo cálculo de Dimensão Fractal da paisagem do Rio Pitangui na Escarpa Devoniana, Ponta Grossa, PR.
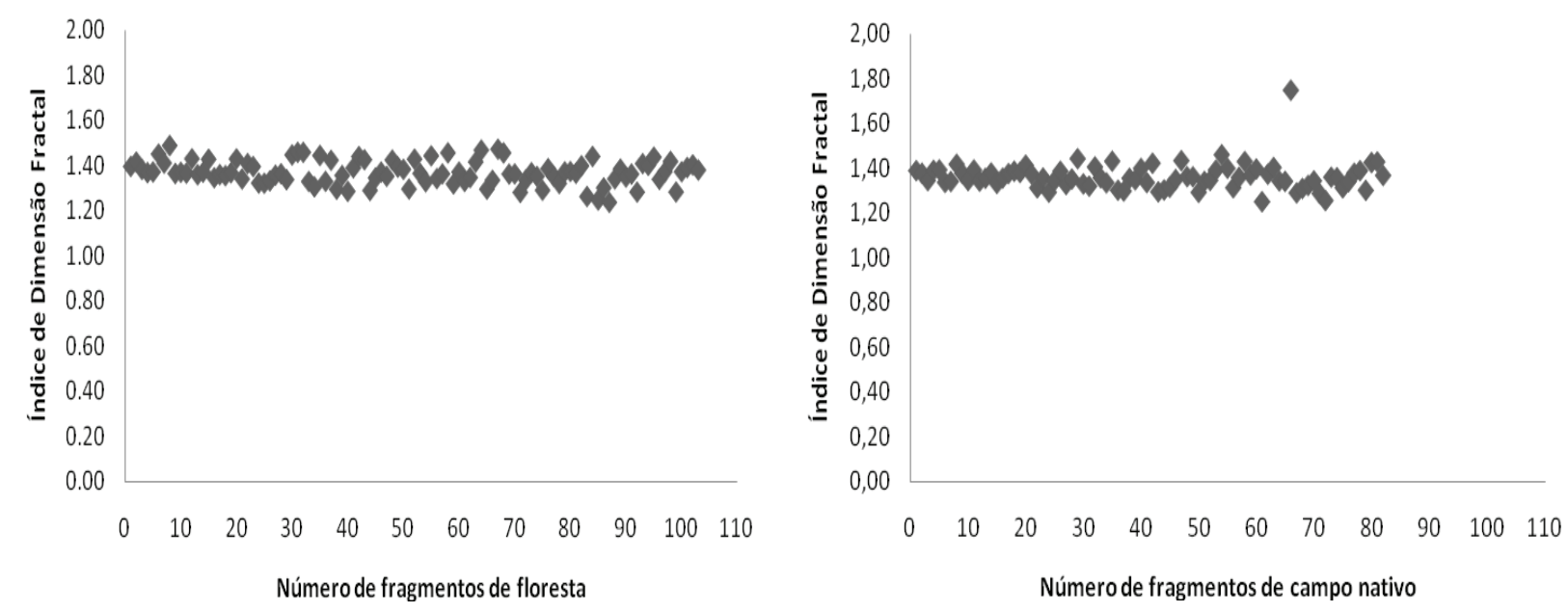

Elaboração dos autores. 
Os dados de IC e FRACT combinados indicam que uma parte dos fragmentos possui formato mais alongado e irregular, principalmente na porção norte da área estudada, onde a diminuição de habitat pela conversão de áreas naturais para a agricultura é mais intensa. Por conseqüência, a fragmentação ocasionada pode provocar a diminuição do número de indivíduos de uma população, favorecendo a perda de variação genética. Assim a população remanescente passa a ter um tamanho menor que o mínimo adequado para que o mesmo possa ter sua normal continuidade e evolução (KAGEYAMA, et al., 1998). Outro fator agravante para essa situação é o efeito de borda, que ocorre onde as áreas de habitat estão expostas às condições externas, na fronteira habitat/matriz. $\mathrm{O}$ aumento das áreas de borda favorece espécies generalistas, muitas vezes parasitas e predadoras, que tendem a excluir as espécies de interior por competição (METZGER, 1999). Ainda, a importância do efeito de borda é intensificada à medida que o tamanho médio dos fragmentos diminui, portanto, para as áreas pequenas com alto IC, tanto florestais quanto campestres, a extensão da borda atinge todo o fragmento (METZGER, 1999).

Tratando-se de elementos funcionais da paisagem do Compartimento 3, a UP florestal apresentou número relativamente maior de trampolins e corredores do que a UP campestre, devido, novamente, ao padrão de distribuição das áreas naturais nesta região, influenciados pelos fatores geológicos, pedológicos, climáticos e hidrológicos peculiares dos Campos Gerais, que condicionam o desenvolvimento dos capões de floresta encaixados em cânions e depressões, frequentemente isolados, envolvidos pela matriz ou pelos campos (Figuras 6).

Figura 6: Classificação dos elementos da paisagem (EP) florestal da bacia do Rio Pitangui na Escarpa Devoniana, Ponta Grossa, PR.

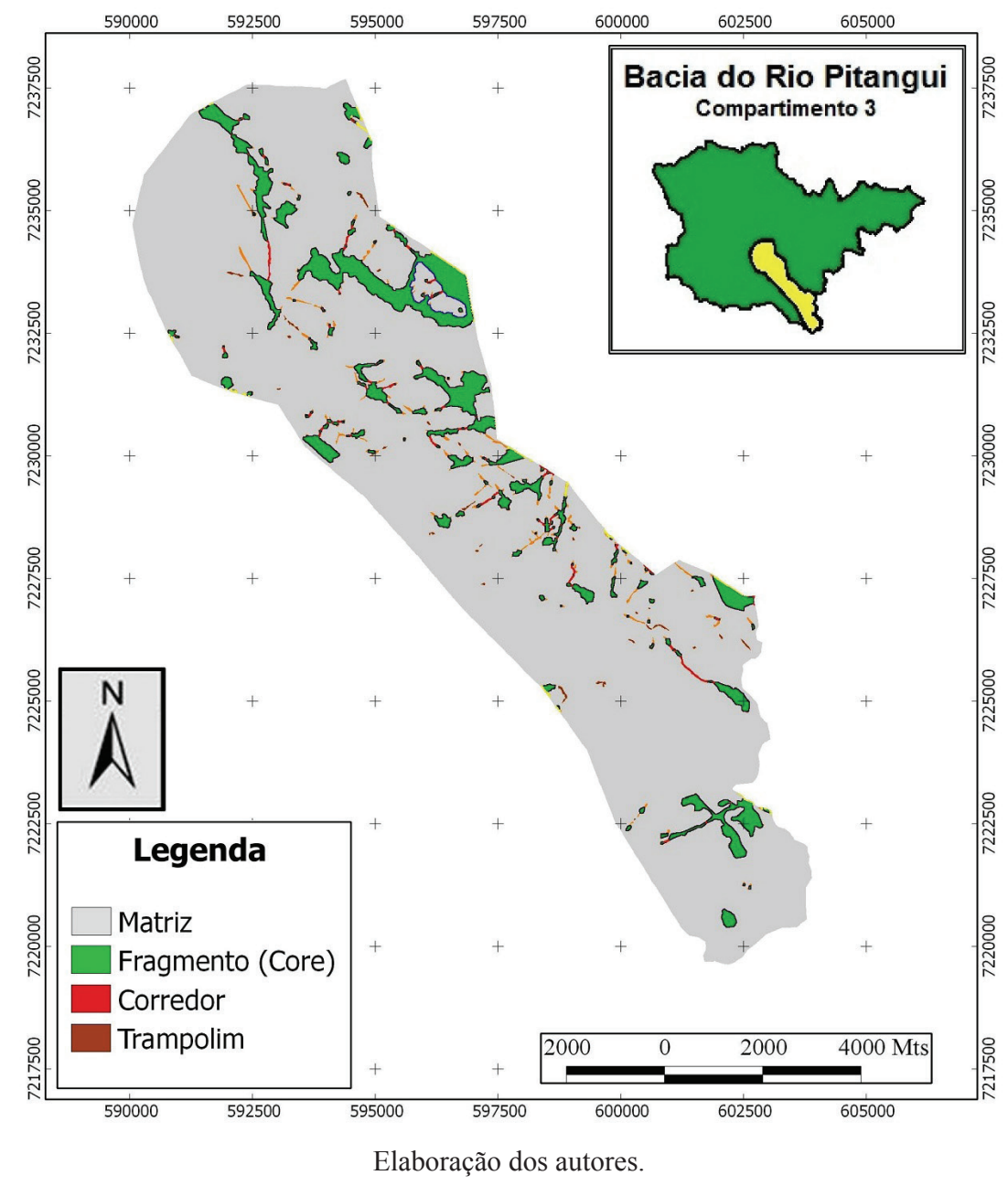

Soc. \& Nat., Uberlândia, 25 (3): 567-579, set/dez/2013 
Nas áreas campestres, são evidentes os extensos fragmentos contínuos, interrompidos de forma natural pelas fraturas geológicas da tectônica do Planalto, ou de forma antrópica por estradas, pastagens e cultivos (Figuras 7), os corredores e os trampolins são mais frequentes nas áreas mais impactadas, na porção norte da área de estudo.

Figura 7: Classificação dos elementos da paisagem campestre da bacia do Rio Pitangui na Escarpa Devoniana, Ponta Grossa, PR.

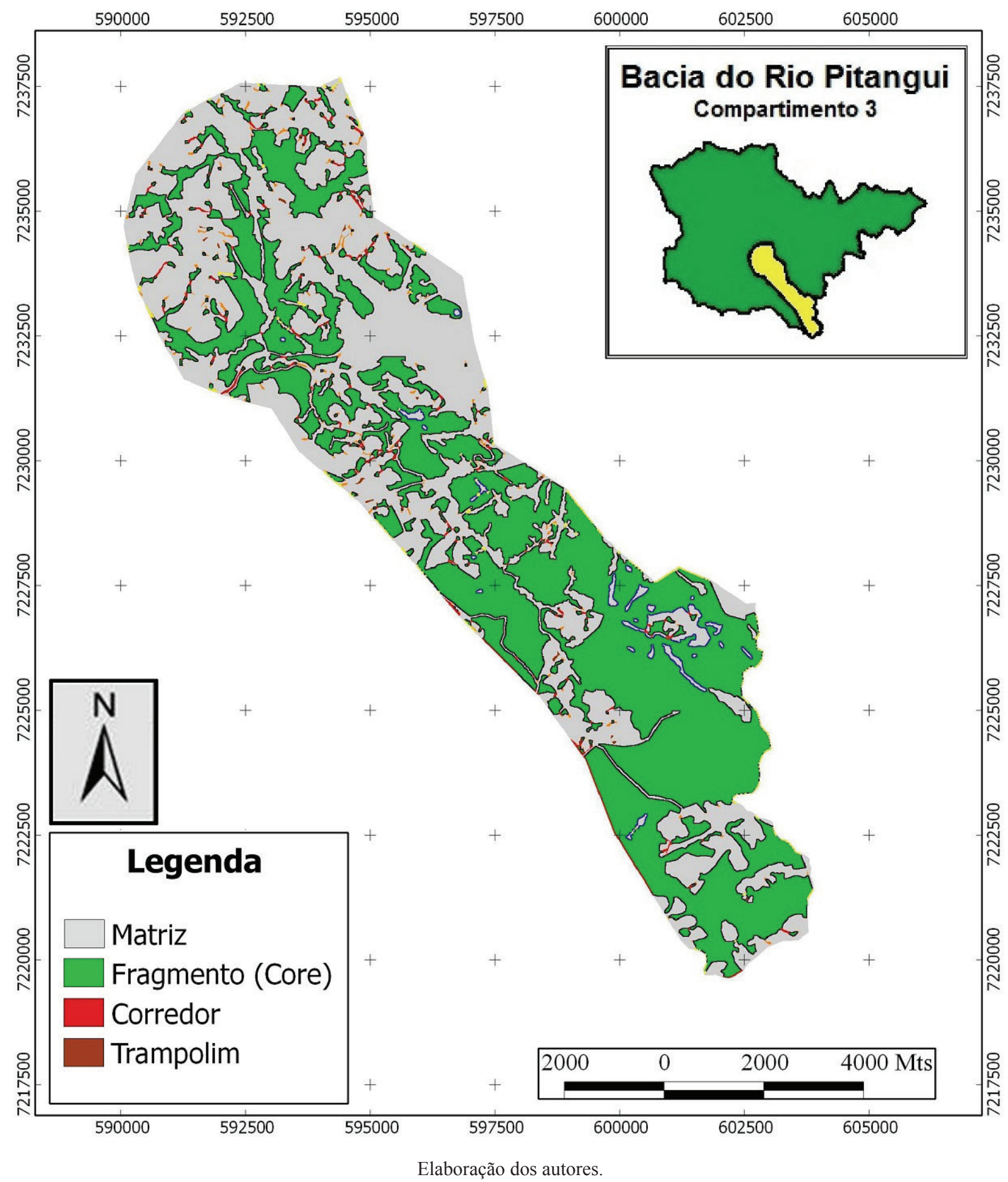




\section{CONCLUSÕES}

As áreas naturais da bacia do Pitangui sobre a Escarpa Devoniana apresentaram condições espaciais favoráveis no que se refere à manutenção da biodiversidade. Embora mais da metade dos fragmentos sejam inferiores a 10 ha, existem áreas campestres extensas atuando como áreas-fonte, uma vez que há predominância das áreas naturais na paisagem. Isso porque o uso da terra nas áreas apresenta restrições devido aos tipos de solo e relevo que dificulta a agricultura, e desse modo, mantém a cobertura vegetal nativa em grandes extensões.

A configuração do mosaico campo-floresta com prevalência campestre é natural para as áreas deste reverso de Cuesta devido às condições climáticas, geológicas e pedológicas da região. Já a relação espacial entre as áreas naturais, especialmente as campestres, com a matriz antropizada, reflete as formas de uso e ocupação do solo, onde a dimensão apresentada pelos fragmentos é resultado da intensidade de supressão da vegetação nativa dessas áreas.

Há uma discordância entre as porções norte e sul das áreas estudadas referindo-se à fragmentação de habitats. Nas áreas ao norte a remoção da vegetação nativa é mais intensificada, o que agrava os efeitos de borda, enquanto a porção sul apresenta fragmentos mais extensos, estes mais favoráveis à manutenção da biodiversidade nas áreas campestres da Escarpa Devoniana.

A classificação dos EPs em trampolins, corredores e fragmentos, remetem ao padrão de distribuição das áreas naturais nesta região, influenciados pelos fatores geológicos, pedológicos, climáticos e hidrológicos peculiares dos Campos Gerais. Os capões de floresta na área, encaixados em cânions e depressões, frequentemente apresentam formas alongadas, ou então pequenas e arredondadas. Já as áreas campestres apresentam-se em grandes fragmentos contínuos, interrompidos de forma natural pelas fraturas geológicas da tectônica do Planalto, ou de forma antrópica por estradas, pastagens e cultivos.

\section{AGRADECIMENTOS}

$\mathrm{O}$ artigo resulta de pesquisa financiada pela CAPES - Coordenação de Aperfeiçoamento de Pessoal de Nível Superior, Brasil.

\section{REFERÊNCIAS}

BEHLING, H. Late Quaternary vegetation, climate and fire history in the Araucaria forest and campos region from Serra Campos Gerais (Paraná), South Brazil. Rev.Paleobot.Palynol., v.97, p.109-121, 1997.

BORGES, L.F.R.; SCOLFORO, J.R.; OLIVEIRA, A.D.; MELLO, J.M.; ACERBI JUNIOR, F.W.; FREITAS, G.D. Inventário de fragmentos florestais nativos e propostas para seu manejo e o da paisagem. Revista Cerne, v. 10, n.1, p. 22-38, 2004.

CASIMIRO, P.C. Uso do Solo - Ecologia da Paisagem, Quantificação da Estrutura da Paisagem para Análise de Padrões Espaciais - Concelho de Mértola. GeoInova, Lisboa, n. 4, p. 125-157, 2001.

CORDEIRO, J.L.P.; HASENACK, H. Cobertura vegetal atual do Rio Grande do Sul. In: PILLAR, V. de P.; MULLER, S.C.; CASTILHOS, Z.M.S.; JACQUES, A.V.A. (Eds.). Campos sulinos: conservação e uso sustentável da biodiversidade. Brasília: MMA, 2009. cap.23, p.285-299.

CRUZ, G.C.F. Alguns aspectos do clima dos Campos Gerais. In: MELO, M.S.; MORO, R.S.; GUIMARÃES, G.B. (Eds.). Patrimônio natural dos Campos Gerais do Paraná. Ponta Grossa: Ed. UEPG, 2007. p. 59-72.

DALAZOANA, K. Espacialização dos campos nativos na Escarpa Devoniana do Parque Nacional dos Campos Gerais, Paraná. Ponta Grossa, 2010. Dissertação (Mestrado em Gestão do Território) Universidade Estadual de Ponta Grossa. 2010.

EMBRAPA - Empresa Brasileira de Pesquisa Agropecuária. Mapa pedológico do Estado do Paraná: arquivo digital. Rio de Janeiro: EMBRAPA, 2002. (CD-ROM). 
FORMAN, R.T.T.; GODRON, M. Patches and structural components for a landscape ecology. Bioscience, v.31, n.10, p.733-740, 1981.

FORMAN, R.T.T.; GODRON, M. Landscape ecology. New York: John Wiley \& Sons, 1986. 619p.

GRANDO JR, E.; BORNSCHEIN, M.; MORO, R.S.; CARMO, M.B. do; BARBOLA, I.F.; TARDIVO, R.C. Campos Gerais: Norte e Sul. In: BILENCA, D.N.; MINARRO, F. Identificación de áreas valiosas de pastizal (AVPs) em las Pampas y campos de Argentina, Uruguay y sur de Brasil. Buenos Aires: FVSA, 2004. p.206-209.

IBGE - Instituto Brasileiro de Geografia e Estatística. Manual Técnico da Vegetação Brasileira. Rio de janeiro, 2012. 275p.

KAGEYAMA, P. Y.; GANDARA, F. B.; SOUZA, L. M. I. Conseqüências genéticas da fragmentação sobre populações de espécies arbóreas. Série Técnica IPEF, v.12, n.32, 1998, p.65-70.

MMA/SBF. Biodiversidade Brasileira: avaliação e identificação de áreas prioritárias para conservação, utilização sustentável e repatriação de benefícios da biodiversidade brasileira. MMA/SBF: Brasília, 2002.

MAACK, R. Geografia física do Estado do Paraná. Curitiba: Imprensa Oficial, 2002. 440p.

McGARIGAL, K.; MARKS, B. J. FRAGSTATS: spatial pattern analysis program for quantifying landscape structure. Gen. Tech. Report PNW-GTR-351, USDA Forest Service, Pacific Northwest Research Station, Portland, OR. 1995. 122 p.

MELO, M.S.; GUIMARAES, G.B.; SANTANA, A.C. Fisiografia da bacia do Rio Pitangui. In: GEALH, A.M.; MELO, M.S.; MORO, R.S. (Orgs.). Pitangui, rio de contrastes: seus lugares, seus peixes, sua gente. Ponta Grossa: Ed. UEPG, 2010. Cap. 1, p. 11-21.
METZGER, J.P. Estrutura da paisagem e Fragmentação: Análise Bibliográfica. Academia Brasileira de Ciências. V.71, (3-I) 1999. p. 445-462.

METZGER, J. P. 2001. O que é ecologia de paisagens? Biota Neotropica, v. 1, números 1 e 2, 2001. Disponível em: http://www.biotaneotropica.org.br/v1n12/ pt/abstract? mthematic-review + BN00701122001. Acesso em 9 de novembro de 2010.

NANUNCIO, V.M. Análise da fragmentação da vegetação florestal de Piraí da Serra, Campos Gerais do Paraná. Ponta Grossa, 2009. Dissertação (Mestrado em Gestão do Território) - Universidade Estadual de Ponta Grossa. 2009.

PEREIRA, T.K.; MORO, R.S.; OLIVEIRA, E.D. Compartimentação prévia da paisagem do rio Pitangui, Ponta Grossa, Paraná. In: SIMPOSIO PARANAENSE DE PÓS-GRADUAÇÃO EM GEOGRAFIA. Curitiba: 2010. Anais...Curitiba, 2010.

RIBEIRO, M.C.; METZGER, J.P.; MARTENSEN, A.C.; PONZONI, F.J.; HIROTA, M.M. The Brazilian Atlantic Forest: How much is left, and how is the remaining forest distributed? Implications for conservation. Biological Conservation, v.142, n. 6, p. 1141-1153, June 2009.

ROCHA, C.H.; WEIRICH NETO, P.H. Padrões de uso das terras e implicações ambientais. In: GEALH, A.M.; MELO, M.S.; MORO, R.S. (Orgs.). Pitangui, rio de contrastes: seus lugares, seus peixes, sua gente. Cap. 2. Ponta Grossa: Ed. UEPG, 2010. p. 23-41.

SANTOS, R.M.S.; MUNIZ, D.B.; BERGAMINI, L.L. Há efeito de borda resultante da fragmentação florestal sobre as espécies Astrocarium sciophilum (Miq.) Pulle (Arecaceae) e Attalea attaleoides (Barb. Rodr.) Wess. Boersi (Areacaceae). In: I SEMINÁRIO INTERNACIONAL DE CIÊNCIAS DO AMBIENTE E SUSTENTABILIDADE NAAMAZÔNIA. Manaus, 2010. Anais ... Manaus, 2010. p. 1-6.

ZILLER S.R.; GALVÃO, F. A degradação da Estepe Gramíneo-Lenhosa no Paraná por Contaminação Biológica de Pinus elliotti e P. taeda. Curitiba, PR. Revista Floresta, v. 32, n. 1, p.41-47, 2002. 